\title{
Evaluation of Extracorporeal Shockwave Lithotripsy in the Management of Renal and Ureteral Calculi
}

\section{Cyril Kamadjou ${ }^{1,2 *}$, Calson Ambomatei ${ }^{3}$, Achille Mbassi ${ }^{4}$, Annie Kameni ${ }^{1}$, Dolly Bilonda Kolela ${ }^{1}$, Fru Angwafor ${ }^{5}$}

\author{
${ }^{1}$ Medical and Surgical Center of Urology, Douala, Cameroon \\ ${ }^{2}$ Faculty of Medicine and Pharmaceutical Sciences, Department of Surgery and Specialities, University of Douala, Douala, Cameroon \\ ${ }^{3}$ Elisabeth Glaser Pediatric AIDS Foundation, Buea, Cameroon \\ ${ }^{4}$ Central Hospital, Yaounde, Cameroon \\ ${ }^{5}$ Coordinator Urology Residency Program, Faculty of Medicine and Biomedical Sciences, University of Yaounde, Yaounde, Cameroon \\ Email: ${ }^{*}$ cyrkamadjou@yahoo.fr
}

How to cite this paper: Kamadjou, C., Ambomatei, C., Mbassi, A., Kameni, A., Kolela, D.B. and Angwafor, F. (2021) Evaluation of Extracorporeal Shockwave Lithotripsy in the Management of Renal and Ureteral Calculi. Open Journal of Urology, 11, 474-485.

https://doi.org/10.4236/oju.2021.1112048

Received: July 27, 2021

Accepted: December 20, 2021

Published: December 23, 2021

Copyright $\odot 2021$ by author(s) and Scientific Research Publishing Inc. This work is licensed under the Creative Commons Attribution International License (CC BY 4.0).

http://creativecommons.org/licenses/by/4.0/

\section{Open Access}

\begin{abstract}
Aim: To evaluate the efficacy of extracorporeal lithotripsy in the management of renal and ureteric calculi in a urology center in Douala, Cameroon. Materials and Methods: This is a retrospective study carried out over six years, between January 2014 and December 2020. All the patients were treated using a Direx Integra lithotripter, with the number of shockwaves ranging from 1200 to 3500 , without anaesthesia and were discharged a few hours after the procedure on the same day. In a majority $(63.75 \%)$ of the cases, the calculi were incidental findings. A Double-J stent was indicated in two patients and preceded extracorporeal lithotripsy because of renal colic and signs of urinary tract infection. Results: We recruited a total of 122 patients with a mean age of $42.19 \pm 13.08$. We had $65(53.3 \%)$ males and all patients had at least one calculus confirmed by CT scan with a mean size of $13.84 \pm 4.17 \mathrm{~mm}, 85$ (69.7\%) patients became completely stone-free after a maximum of four sessions of extracorporeal lithotripsy (ESWL). 21 (17.2\%) patients had intermediate results, being asymptomatic and/or having less than three residual fragments that measured less than $4 \mathrm{~mm}$. The failure rate was $13.9 \%$, with 17 patients still having more than three fragments measuring more than $4 \mathrm{~mm}$ after 4 ESWL sessions. 1 (0.8\%) had septic shock as a post ESWL complication while 6 (4.9\%) benefitted from a complimentary medical and/or surgical treatment (double J stent placement). Conclusion: The management of renal and ureteral calculi through extracorporeal lithotripsy in adults seems to be particularly effective for renal calculi measuring less than $20 \mathrm{~mm}$ and ureteral calculi measuring less than $15 \mathrm{~mm}$. Extracorporeal lithotripsy, which can be
\end{abstract}


performed on an outpatient basis (and without anaesthesia) is associated with minimal complications, and remains the option of choice for most upper urinary tract calculi.

\section{Keywords}

Renal and Ureteric Calculi, Extracorporeal Lithotripsy, Double-J Stent

\section{Introduction}

The use of Extracorporeal shockwave lithotripsy (ESWL) for the management of renal and upper urinary tract calculi started as far back as the 1980's [1].

ESWL is a very important and highly effective method in the treatment of calculi of the upper urinary tract and upper ureter. It effectively fragments these calculi, which in turn pass completely by the end of 3 months in $77.4 \%$ of the patients with single stones according to a report by Drach et al. in 1986 [2]. Over the years, ESWL has gained rapid acceptance worldwide because of its ease of use, noninvasive nature, high efficacy in treating kidney and ureteral stones, and wide availability of lithotriptors [3]. ESWL is effective in fragmenting kidney stones because of some inherent properties of the shock waves. The most important of these properties are the ability to generate mechanical stress in brittle material, the potential to be transmitted freely and propagated through the body without energy loss and without causing damage when passing through, the ability to be focused, and the ease and reliability of reproducibility for clinical use [1]. The overall goal in the management of kidney and ureteric calculi is to bring the patients to a completely stone-free status while minimizing morbidity and mortality. Other non-invasive methods are also employed in the management of calculi of the upper urinary tract and upper ureter. These include percutaneous nephrolithotomy (PCNL), ureteroscopy (URS), laparoscopy and robotic surgery [4]. In the absence of these non-invasive or minimally invasive methods, or where they fail, other more invasive procedures can be used including open surgery [4]. As treatment modality for adult patients with ureteral stones, the American Urological Association (AUA) recommends watchful waiting for patients with uncomplicated ureteral stones $\leq 10 \mathrm{~mm}$, URS for patients with mid or distal ureteral stones who require intervention and for patients with suspected cystine or uric acid ureteral stones who fail medical expulsive therapy (MET) [4]. In the case of adult patients with renal stones, the AUA recommends SWL or URS for symptomatic patients with a total non-lower pole renal stone burden $<20 \mathrm{~mm}$, PCNL for symptomatic patients with a total renal stone burden $>20 \mathrm{~mm}$ [4]. However, because of limited resources in our setting and coupled with the expensive nature of PCNL in terms of equipment and expertise, ESWL is still being performed on patients with renal stone size above 20 $\mathrm{mm}$.

ESWL has been proven to be an ideal modality for the management of kidney 
stones. The advantages of this method include the fact that it is non-invasive, has a greater success rate in the management of proximal ureteral calculi, the reduced need for secondary calculi-clearing procedures, a significantly low hospitalization rate, and significantly short hospitalization [5] [6] [7].

\section{Methods and Materials}

We carried out a retrospective study over a period of six years, from January 2014 to December 2020 at the Centre medico-chirugicale d'urologie, which is located in Bali, Douala. This is a medical center that specializes in minimally-invasive surgery and surgical management of urological pathologies using innovative techniques. We consulted the clinical records of patients who had calculi in the kidneys, at the junction between the renal pelvis and the ureter, and at the lumbar segment of the ureter. The calculi were managed using a Direx Integra lithotripter in all study participants. The image of the lithotripter is presented in Figure 1. The number of shockwaves ranged from 1500 to 3500, 2500 to 3200,2500 to 3000 , and 1200 to 3000 during the first, second, third, and fourth sessions, respectively. All the interventions were carried out by the same surgeon, assisted by a nurse. General anaesthesia was not used in any patient, but all patients had an intravenous line prior to the ESWL sessions that permitted the administration of analgesics in case of pains. All patients were treated on an outpatient basis. Drainage using a Double-J stent preceded extracorporeal lithotripsy in some patients. We consulted a total of 122 records of patients from January 2014 to December 2020 at the Centre medico-chirugicale d'urologie. The data we collected from the patients' clinical records included patients' age, gender, clinical profile, relevant medical history, size of the calculi, localization of the calculi as confirmed by imaging, and outcome of lithotripsy. All the study participants had at least one kidney or ureteric stone. The imaging method used for confirmation of the stones before ESWL in all patients was the CT scan and $\mathrm{X}$-rays were performed following the procedure to confirm stone clearance. $\mathrm{Pa}$ tients were considered stone-free if no stone was visible on imaging fifteen days after their last ESWL session. Residual fragments were defined as the presence of at least three residual fragments of at most $4 \mathrm{~mm}$ following ESWL.
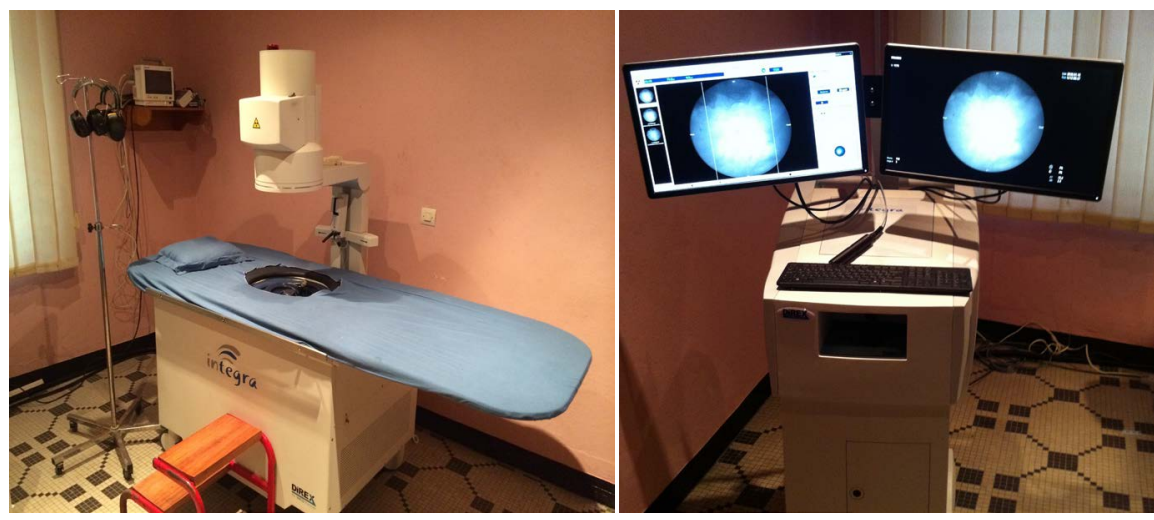

Figure 1. Image of the Direx Integra lithotripter used in the treatment of the patients. 
Continuous variables were presented as mean values and standard deviations (for normally distributed data) and medians with interquartile ranges (for skewed data). On the other hand, categorical variables were presented as frequencies and percentages.

\section{Results}

\subsection{Patients' Profile}

Of the 122 files we included for analysis, 67 files belonged to men and 55 belonged to women. The mean age of these patients was 42.19 (13.08) years. Although all the patients underwent extracorporeal lithotripsy, drainage using a Double-J stent preceded extracorporeal lithotripsy in two patients because they had renal colic with urinary tract infection as a complication on presentation.

The mean size of the stones was 13.84 (4.17) $\mathrm{mm}$. As for the localisation of these stones, $84(68.9 \%)$ were found in the renal pelvis (30 in the upper pole, 31 in the middle pole and 23 in the inferior pole), 21 (17.2\%) were found at the junction between the renal pelvis and the ureter, while 17 (13.9\%) were found in the lumbar ureter. As concerns the laterality of the stones, 65 (53.3\%) of them were located on the right side of the body, while 56 (46.7\%) of them were located on the left side. As for the number of shockwave sessions, there was one session in $34(27.9 \%)$ cases, two sessions in $62(50.8 \%)$ cases, three sessions in $20(16.4 \%)$ cases, and four sessions in $6(4.9 \%)$ cases. Twenty-four patients $(19.7 \%)$ had double-J stents pre-op, while three patients $(2.5 \%)$ had double-J stents post-op.

Concerning the outcomes of calculi following ESWL, 84 (68.9\%) patients were stone-free, 21 (17.2\%) had residual fragments, while 17 (13.9\%) experienced therapeutic failure. Four (3.3\%) patients received medical treatment as complementary therapy, while 2 patients (1.6\%) received surgical treatment as complementary therapy. A total of 121 (99.2\%) patients experienced no complications after ESWL, while 1 patient (0.8\%) experienced septic shock as a complication.

Although all the patients underwent extracorporeal lithotripsy, 4 (3.3\%) patients received medical treatment as complementary therapy, while $2(1.6 \%)$ were treated with double-J stent placement as complimentary surgical therapy. The profiles of the 122 patients involved in this study are presented in Table 1.

\subsection{Success Rate Following ESWL in the General Population}

In general, $32(26.2 \%)$ patients were stone-free after the first session of ESWL. After four sessions, the percentage of participants with stone-free kidneys increased to $68.9 \%$ (84 patients) (Table 2) (Figure 2).

\subsection{Success Rate According to Stone Location}

Nineteen kidney stones were successfully removed from the junction between the pelvis and the ureter, 5 from the inferior pole of the kidney, 21 from the middle pole of the kidney, 23 from the superior pole of the kidney, and 16 from the lumbar portion of the ureter (Table 3 ). 
Table 1. Patient profile.

\begin{tabular}{|c|c|c|c|}
\hline VARIABLE & $\begin{array}{c}\text { MALE } \\
(\mathrm{n}=67) \\
\mathrm{N}^{\circ}(\%)\end{array}$ & $\begin{array}{c}\text { FEMALE } \\
(\mathrm{n}=55) \\
\mathrm{N}^{\bullet}(\%)\end{array}$ & $\begin{array}{c}\text { TOTAL } \\
(\mathrm{n}=122) \\
\mathrm{N}^{\bullet}(\%)\end{array}$ \\
\hline Mean age (SD) & $40.85(13.19)$ & $43.72(12.91)$ & $42.19(13.08)$ \\
\hline \multicolumn{4}{|l|}{ Initial presentation } \\
\hline No symptom & $41(63.1)$ & $39(68.4)$ & $80(65.6)$ \\
\hline Acute nephritic colic & $22(33.8)$ & $16(28.1)$ & $38(31.1)$ \\
\hline Acute nephritic colic plus sepsis & $2(3.1)$ & $0(0.0)$ & $2(1.6)$ \\
\hline Sepsis only & $0(0.0)$ & $2(3.5)$ & $2(1.6)$ \\
\hline Mean size of stone (SD) & $13.88(3.83)$ & $13.79(4.56)$ & $13.84(4.17)$ \\
\hline \multicolumn{4}{|l|}{ Localization of stone } \\
\hline JPU & $12(18.5)$ & $9(15.8)$ & $21(17.2)$ \\
\hline PI & $10(15.4)$ & $13(22.8)$ & $23(18.9)$ \\
\hline $\mathrm{PM}$ & $18(27.7)$ & $12(21.1)$ & $31(25.4)$ \\
\hline PS & $15(23.1)$ & $16(28.1)$ & $30(24.6)$ \\
\hline UL & $10(15.4)$ & $7(12.3)$ & $17(13.9)$ \\
\hline \multicolumn{4}{|l|}{ Laterality of the affected kidney $n$} \\
\hline Right & $31(47.7)$ & $34(59.6)$ & $65(53.3)$ \\
\hline Left & $34(52.3)$ & $23(40.4)$ & $56(46.7)$ \\
\hline \multicolumn{4}{|l|}{ Number of shockwave sessions } \\
\hline One shockwave session only & $17(26.2)$ & $17(29.8)$ & $34(27.9)$ \\
\hline Two shockwave sessions only & $35(53.8)$ & $27(47.4)$ & $62(50.8)$ \\
\hline Three shockwave sessions only & $10(15.4)$ & $10(17.5)$ & $20(16.4)$ \\
\hline Four shockwave sessions only & $3(4.6)$ & $3(5.3)$ & $6(4.9)$ \\
\hline Number of clients with JJ stents pre-op & $13(20.0)$ & $11(19.3)$ & $24(19.7)$ \\
\hline Number of clients with JJ stents post-op & $2(3.1)$ & $1(1.8)$ & $3(2.5)$ \\
\hline \multicolumn{4}{|l|}{ Outcome of Calculi following ESWL } \\
\hline Stone-free & $42(64.6)$ & $42(73.7)$ & $84(68.9)$ \\
\hline Residual fragments & $11(16.9)$ & $10(17.5)$ & $21(17.2)$ \\
\hline Failure & $12(18.5)$ & $5(8.8)$ & $17(13.9)$ \\
\hline \multicolumn{4}{|l|}{ Complementary treatment $\mathrm{n}(\%)$} \\
\hline Medical treatment & $2(3.1)$ & $2(3.5)$ & $4(3.3)$ \\
\hline Surgical treatment & $1(1.5)$ & $1(1.8)$ & $2(1.6)$ \\
\hline \multicolumn{4}{|l|}{ Post-ESWL complication n (\%) } \\
\hline No complication & $61(93.8)$ & $54(94.7)$ & $115(94.3)$ \\
\hline CNA & $3(4.6)$ & $3(5.3)$ & $6(4.9)$ \\
\hline Septic shock & $1(1.5)$ & $0(0.0)$ & $1(0.8)$ \\
\hline
\end{tabular}

Table 2. Success rate following ESWL in the general population.

\begin{tabular}{cccc}
\hline & Male n (\%) & Female n (\%) & Total n (\%) \\
\hline After one session & $16(24.6)$ & $16(28.1)$ & $32(26.2)$ \\
After two sessions & $37(56.9)$ & $36(63.2)$ & $73(59.8)$ \\
After three sessions & $41(63.1)$ & $42(73.7)$ & $83(68.0)$ \\
After four sessions & $42(64.6)$ & $42(73.7)$ & $84(68.9)$ \\
\hline
\end{tabular}


Table 3. Success rate according to stone location.

\begin{tabular}{cccccc}
\hline & $\begin{array}{c}\text { First session } \\
\mathbf{n}(\%)\end{array}$ & $\begin{array}{c}\text { Second } \\
\text { session } \mathbf{n}(\%)\end{array}$ & $\begin{array}{c}\text { Third session } \\
\mathbf{n}(\%)\end{array}$ & $\begin{array}{c}\text { Fourth } \\
\text { session } \mathbf{n}(\%)\end{array}$ & $\begin{array}{c}\text { Total } \mathbf{n} \\
(\%)\end{array}$ \\
\hline JPU (n= 21) & $7(33.3)$ & $8(38.1)$ & $4(19.0)$ & $0(0.0)$ & $19(90.5)$ \\
PI (n= 23) & $3(13.0)$ & $2(8.7)$ & $0(0.0)$ & $0(0.0)$ & $5(21.7)$ \\
PM (n=31) & $9(29.0)$ & $7(22.5)$ & $4(12.9)$ & $1(3.2)$ & $21(67.7)$ \\
PS (n=30) & $8(26.7 .0)$ & $14(46.7)$ & $1(3.3)$ & $0(0.0)$ & $23(76.7)$ \\
UL (n=17) & $5(29.4)$ & $10(58.8)$ & $1(5.9)$ & $(0.0)$ & $16(94.1)$ \\
TOTAL (n=122) & $32(26.2)$ & $41(33.6)$ & $10(8.2)$ & $1(0.8)$ & $84(68.9)$ \\
\hline
\end{tabular}

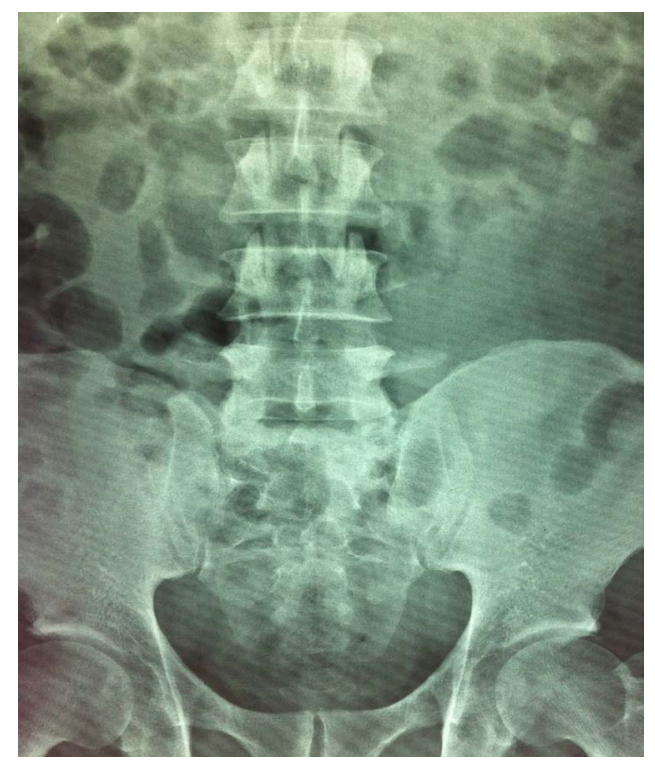

(a)

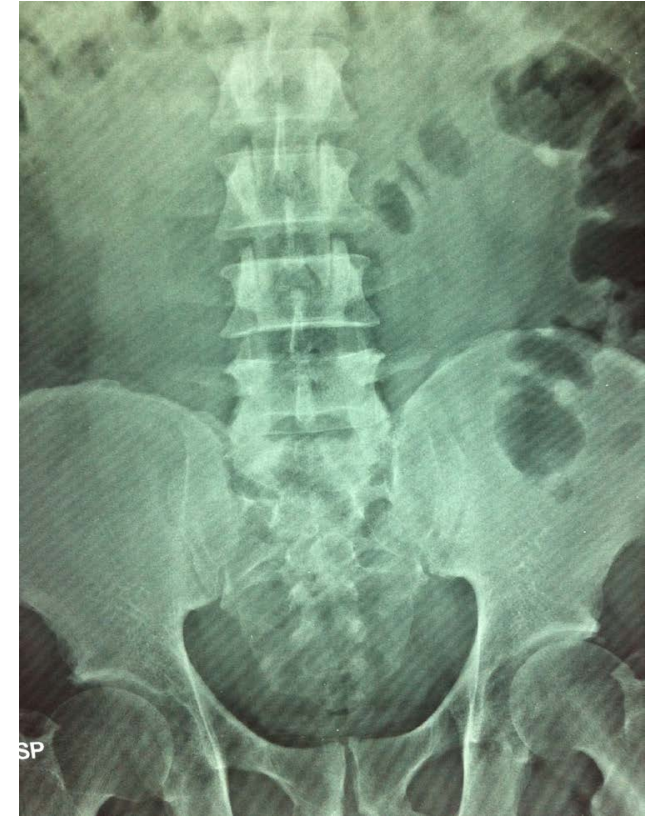

(b) 


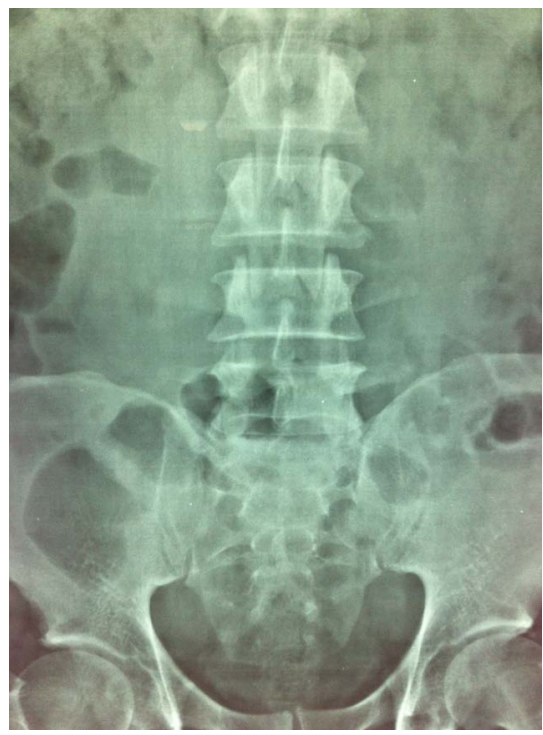

(c)

Figure 2. (a) Left non obstructive renal stone before ESWL sessions; (b) After first session of ESWL; (c) After second session of ESWL.

\subsection{Success Rate According to Stone Size}

Of the 32 stones measuring $5-10 \mathrm{~mm}, 24$ (75.0\%) were removed during the first session of ESWL and 1 was removed after the second session, giving a stone-free success rate of $78.1 \%$ after two sessions. Of the 57 stones measuring $11-15 \mathrm{~mm}$, 8 (14.0\%) were removed during the first session, 32 during the second session, and 2 during the third session of ESWL, giving an overall stone-free success rate of $73.7 \%$. Of the 23 stones measuring $16-20 \mathrm{~mm}$, none was removed during the first session, 8 were removed during the second session, 5 during the third session, and 1 during the fourth session with an overall stone-free success rate of $60.9 \%$. Of the 10 stones measuring $21-25 \mathrm{~mm}, 3$ (30.0\%) were removed only after the third ESWL session and none removed after the fourth session were removed during the third session of ESWL (Table 4).

\subsection{Success Rate According to Initial Presenting Symptoms}

Of the 80 patients that had no symptom at initial presentation, 20 (25.0\%) had their stones removed during the first session of ESWL, 23 had their stones removed during the second session, 5 during the third session, and 1 during the fourth session, giving a stone-free success rate of $61.3 \%$.

Of the 38 patients that had acute nephritic colic as initial symptom, 12 (31.6\%) had their stones removed during the first session of ESWL, 16 had their stones removed during the second session, and 4 during the third session, with an overall stone-free success rate of $84.2 \%$. Only 1 (50\%) of the 2 patients who presented with acute nephritic colic and sepsis had the stone removed and this was during the second session of ESWL. The 2 patients who presented with sepsis were completely stone free after the second session for one and after the third session for the other, with an ESWL success rate of 100\% (Table 5). 
Table 4. Success rate according to stone size.

\begin{tabular}{|c|c|c|c|c|}
\hline & $\begin{array}{c}\text { After one } \\
\text { session } n(\%)\end{array}$ & $\begin{array}{c}\text { After two } \\
\text { sessions n (\%) }\end{array}$ & $\begin{array}{c}\text { After three } \\
\text { sessions n (\%) }\end{array}$ & $\begin{array}{c}\text { After four } \\
\text { sessions n (\%) }\end{array}$ \\
\hline $5-10(n=32)$ & $24(75.0)$ & $25(78.1)$ & $25(78.1)$ & $25(78.1)$ \\
\hline $11-15(n=57)$ & $8(14.0)$ & $40(70.2)$ & $42(73.7)$ & $42(73.7)$ \\
\hline $16-20(n=23)$ & $0(0.0)$ & $8(34.8)$ & $13(56.5)$ & $14(60.9)$ \\
\hline $21-25(n=10)$ & $0(0.0)$ & $0(0.0)$ & $3(30.0)$ & $3(30.0)$ \\
\hline
\end{tabular}

Table 5. Success rate based on initial presenting symptoms.

\begin{tabular}{lcccc}
\hline & $\begin{array}{c}\text { After one } \\
\text { Session } \mathbf{n}(\%)\end{array}$ & $\begin{array}{c}\text { After two } \\
\text { sessions n (\%) }\end{array}$ & $\begin{array}{c}\text { After three } \\
\text { sessions n (\%) }\end{array}$ & $\begin{array}{c}\text { After four } \\
\text { Sessions } \mathbf{n}(\%)\end{array}$ \\
\hline No symptom $(\mathbf{n}=\mathbf{8 0})$ & $20(25.0)$ & $43(53.8)$ & $48(60.0)$ & $49(61.3)$ \\
CAN (n= 38) & $12(31.6)$ & $28(73.7)$ & $32(84.2)$ & $32(84.2)$ \\
CAN + Sepsis $(\mathbf{n}=2)$ & $0(0.0)$ & $1(50.0)$ & $1(50.0)$ & $1(50.0)$ \\
Sepsis $(\mathbf{n}=2)$ & $0(0.0)$ & $1(50.0)$ & $2(10.0)$ & $2(100.0)$ \\
\hline
\end{tabular}

\subsection{Success Rate Based on Initial Presenting Symptoms and Stone Size}

Of the 49 patients who had no symptoms initially and were completely stone-free following ESWL, 28 had stones that measured $5-10 \mathrm{~mm}, 25$ had stones that measured $11-15 \mathrm{~mm}, 5$ had stones that measured $16-20 \mathrm{~mm}$, while 1 had stones that measured $21-25 \mathrm{~mm}$.

Of the 32 patients that had acute nephritic colic and treated successfully with ESWL, 7 had stones that measured $5-10 \mathrm{~mm}, 16$ had stones that measured 11 $15 \mathrm{~mm}, 7$ had stones that measured $16-20 \mathrm{~mm}$, while 2 had stones that measured $21-25 \mathrm{~mm}$. The 1 patient who initially presented with acute nephritic colic and sepsis and became stone free after ESWL had stones measuring $11-15 \mathrm{~mm}$. The two patients that initially presented with sepsis had stones measuring 16 $20 \mathrm{~mm}$ (Table 6).

\section{Discussion}

We used 122 patients to compare the percentage of patients with kidney and ureteric stones who achieved a complete stone-free state after ESWL. We compared the success rate based on the number of shockwave sessions required, stone location, stone size and initial presentation at diagnosis. We obtained a general success rate (patients who became stone-free) of $68.9 \%$ in the general population and $64.6 \%$ and $73.7 \%$ respectively in males and females. This was higher than the $55.2 \%$ gotten by Ze Ondo et al. [8]. This could be explained by the fact that in our study, most of the patients (89) had calculi less than or equal to $15 \mathrm{~mm}$. It has been shown that ESWL is more effective in removing stones of smaller sizes. 
Table 6. Success rate based on initial presenting symptoms and stone size.

\begin{tabular}{cccccc}
\hline & $\begin{array}{c}\mathbf{5}-\mathbf{1 0} \\
(\mathrm{n}=\mathbf{3 2})\end{array}$ & $\begin{array}{c}\mathbf{1 1}-\mathbf{1 5} \\
(\mathrm{n}=\mathbf{5 7})\end{array}$ & $\begin{array}{c}\mathbf{1 6 - 2 0} \\
(\mathrm{n}=\mathbf{2 3})\end{array}$ & $\begin{array}{c}\mathbf{2 1}-\mathbf{2 5} \\
(\mathrm{n}=\mathbf{1 0})\end{array}$ & Total $\mathrm{n}(\%)$ \\
\hline No symptoms & 18 & 25 & 5 & 1 & $49(61.3)$ \\
CAN & 7 & 16 & 7 & 2 & $32(84.2)$ \\
CAN + Sepsis & 0 & 1 & 0 & 0 & $1(50.0)$ \\
Sepsis & 0 & 0 & 2 & 0 & $2(100.0)$ \\
\hline
\end{tabular}

We noticed that after the first ESWL session, just $26.2 \%$ of the patients were stone-free and 52 (42.6\%) required multiple ESWL sessions. After four sessions, therefore, the percentage of patients who were stone-free increased to $68.9 \%$. This is similar to the results published by Al-Abadi et al. (43\% after first ESWL and $61 \%$ requiring repeat ESWL) and Al-Ansari et al. (78\% after first ESWL and 53.1\% requiring repeat ESWL) [9] [10].

In our study, $77.5 \%$ of patients with a calculus of less than $20 \mathrm{~mm}$ who were symptomatic at presentation were stone-free following ESWL. This is higher than the $64.8 \%$ for stones less than $10 \mathrm{~mm}$ and $30 \%$ for those between 10 and 20 $\mathrm{mm}$ reported by Ze Ondo et al. but similar to $82.0 \%$ and $64.5 \%$ for less than 10 $\mathrm{mm}$ and between $10-20 \mathrm{~mm}$ respectively reported by De Marco [8] [11]. The high percentage observed in our study compared to that reported by Ze Ondo could be explained by the fact that the AUA recommends ESWL, based on strong evidence, in the treatment of symptomatic patients with a total non-lower pole renal stone burden $<20 \mathrm{~mm}$ [4]. Also, Ze Ondo et al. did not take the size of the calculi when estimating the success rate of ESWL.

In the present study, $94.1 \%$ and $90.5 \%$ of patients with calculi at the level of the UL and JPU respectively were stone-free after ESWL. A lower success rate was observed with stones located at the PI (21.7\%). Juan et al. reported a stone clearance rate of $57.6 \%$ for inferior pole stones [12]. It has been shown from previous studies that the low success rate observed in inferior pole calculi, compared to calculi found in other locations within the kidney is related to the effects of gravity on the position of the stone and lower calyceal spatial anatomy, rather than of stone disintegration [13].

For stones of the PS and PM, 76.7\% and $67.7 \%$ respectively resolved completely after ESWL sessions. This finding was similar to those obtained by Ze Ondo et al. (65.2\% for PS and PM) [8]. The high success rate experienced with stone of the superior and middle poles of the kidney is due to the significant effect of gravity which makes it easier for fragments to be eliminated following ESWL.

However, the rate of success we had with stones of the PS and PM were lower than the $89.2 \%$ and $90.5 \%$ respectively reported by Coz et al. [14].

ESWL has several advantages mainly owing to its non-invasive nature and its high success rate. In spite of these benefits, several studies have reported acute nephritic colic, renal hematoma, sepsis and septic shock as major complications 
of ESWL [3] [8] [15]. In the present study, the overall rate of complication following ESWL was 5.7\%, with acute colicky pain contributing $4.9 \%$ and septic shock accounting for $0.8 \%$. Out of the 6 patients who had post ESWL colicky pain, $66.7 \%$ were treated medically with analgesics and antispasmodics, while $33.3 \%$ underwent surgical treatment with double J stent placement. In general, complications after an ESWL are caused by the formation and passage of fragments; infections; the effects of shockwaves on renal and non-renal tissues or a combination of these [16]. It has been documented that the development of sepsis after bacteremia in patients who undergo ESWL is relatively low and occurs in less than $1 \%$ of patients, as was the case in our study (0.8\%) [17]. The most common complication that occurs as a result of the direct effect of the shockwaves on the kidney is haemaruria [16]. None of the patients, however, developed a haematoma.

\section{Conclusion}

ESWL has revolutionalized the management of renal and ureteral calculi in adults and it is particularly effective for renal calculi measuring less than $20 \mathrm{~mm}$ and ureteral calculi measuring less than $15 \mathrm{~mm}$. Extracorporeal lithotripsy, which can be performed on an outpatient basis (and without anaesthesia) is associated with minimal complications, and remains the option of choice for most upper urinary tract calculi. The overall success rate of the procedure in the present study was $68.9 \%$, the re-treatment rate was $42.6 \%$ and the overall complication rate was $5.7 \%$.

\section{Conflicts of Interest}

The authors declare no conflicts of interest regarding the publication of this paper.

\section{References}

[1] Chaussy, C., Schüller, J., Schmiedt, E., Brandl, H., Jocham, D. and Liedl, B. (1984) Extracorporeal Shock-Wave Lithotripsy (ESWL) for Treatment of Urolithiasis. Urology, 23, 59-66. https://doi.org/10.1016/0090-4295(84)90243-7 https://www-sciencedirect-com.proxy1.lib.tju.edu/science/article/pii/009042958490 2437

[2] Drach, G.W., Dretler, S., Fair, W., Finlayson, B., Gillenwater, J., et al. (1986) Report of the United States Cooperative Study of Extracorporeal Shock Wave Lithotripsy. The Journal of Urology, 135, 1127-1133. https://doi.org/10.1016/S0022-5347(17)46015-0

[3] Skolarikos, A., Alivizatos, G. and de la Rosette, J. (2006) Extracorporeal Shock Wave Lithotripsy 25 Years Later: Complications and Their Prevention. European Urology, 50, 981-990. https://www.sciencedirect.com/science/article/pii/S0302283806001047 https://doi.org/10.1016/j.eururo.2006.01.045

[4] Kidney Stones: Surgical Management Guideline. American Urological Association. https://www.auanet.org/guidelines/guidelines/kidney-stones-surgical-managementguideline 
[5] Drake, T., Grivas, N., Dabestani, S., Knoll, T., Lam, T., Maclennan, S., et al. (2017) What Are the Benefits and Harms of Ureteroscopy Compared with Shock-Wave Lithotripsy in the Treatment of Upper Ureteral Stones? A Systematic Review. European Urology, 72, 772-786. https://doi.org/10.1016/j.eururo.2017.04.016 https://www.sciencedirect.com/science/article/pii/S030228381730324X

[6] Turna, B., Akbay, K., Ekren, F., Nazlı, O., Apaydın, E., Semerci, B., et al. (2008) Comparative Study of Extracorporeal Shock Wave Lithotripsy Outcomes for Proximal and Distal Ureteric Stones. International Urology and Nephrology, 40, 23-29. https://doi.org/10.1007/s11255-007-9214-X

[7] Ziaee, S.A.M., Halimiasl, P., Aminsharifi, A., Shafi, H., Beigi, F.M.A. and Basiri, A. (2008) Management of 10-15-mm Proximal Ureteral Stones: Ureteroscopy or Extracorporeal Shockwave Lithotripsy? Urology, 71, 28-31.

https://www.sciencedirect.com/science/article/pii/S0090429507020079 https://doi.org/10.1016/j.urology.2007.08.025

[8] Ze Ondo, C., Fall, B., Sow, Y., Thiam, A., Sarr, A., Ghazal, H., et al. (2018) La lithotripsie extracorporelle: Expérience d'un centre Sénégalais. African Journal of Urology, 24, 319-323. https://doi.org/10.1016/j.afju.2018.03.001 https://www.sciencedirect.com/science/article/pii/S1110570418300407

[9] Al-Abadi, E. and Hulton, S.-A. (2013) Extracorporal Shock Wave Lithotripsy in the Management of Stones in Children with Oxalosis-Still the First Choice? Pediatric Nephrology, 28, 1085-1089. https://doi.org/10.1007/s00467-013-2424-9

[10] Al-Ansari, A., As-Sadiq, K., Al-Said, S., Younis, N., Jaleel, O.A. and Shokeir, A.A. (2006) Prognostic Factors of Success of Extracorporeal Shock Wave Lithotripsy (ESWL) in the Treatment of Renal Stones. International Urology and Nephrology, 38, 63-67. https://doi.org/10.1007/s11255-005-3155-Z

[11] De Marco, F. (2019) Extracorporal Shock Wave Lithotripsy Treatment for Kidney Stones: Still a Valid Option. European Urology, 18, e2885. https://linkinghub.elsevier.com/retrieve/pii/S1569905619330635 https://doi.org/10.1016/S1569-9056(19)33063-5

[12] Juan, Y.-S., Shen, J.-T., Wang, C.-J., Chuang, S.-M., Wu, W.-J. and Huang, C.-H. (2005) Impact of Lower Pole Anatomy on Stone Clearance after Shock Wave Lithotripsy. The Kaohsiung Journal of Medical Sciences, 21, 358-364. https://doi.org/10.1016/S1607-551X(09)70134-2

[13] Lingeman, J.E., Siegel, Y.I., Steele, B., Nyhuis, A.W. and Woods, J.R. (1994) Management of Lower Pole Nephrolithiasis: A Critical Analysis. The Journal of Urology, 151, 663-667. https://doi.org/10.1016/S0022-5347(17)35042-5

[14] Coz, F., Orvieto, M., Bustos, M., Lyng, R., Stein, C., Hinrichs, A., et al. (2000) Extracorporeal Shockwave Lithotripsy of 2000 Urinary Calculi with the Modulith SL-20: Success and Failure According to Size and Location of Stones. Journal of Endourology, 14, 239-246. https://doi.org/10.1089/end.2000.14.239

[15] Dhar, N.B., Thornton, J., Karafa, M.T. and Streem, S.B. (2004) A Multivariate Analysis of Risk Factors Associated with Subcapsular Hematoma Formation Following Electromagnetic Shock Wave Lithotripsy. The Journal of Urology, 172, 2271-2274. https://doi.org/10.1097/01.ju.0000143459.03836.2d

[16] D’Addessi, A., Vittori, M., Racioppi, M., Pinto, F., Sacco, E. and Bassi, P. (2012) Complications of Extracorporeal Shock Wave Lithotripsy for Urinary Stones: To Know and to Manage Them-A Review. The Scientific World Journal, 2012, Article ID: 619820. https://www.ncbi.nlm.nih.gov/pmc/articles/PMC3317539 https://doi.org/10.1100/2012/619820 
[17] Müller-Mattheis, V.G., Schmale, D., Seewald, M., Rosin, H. and Ackermann, R. (1991) Bacteremia during Extracorporeal Shock Wave Lithotripsy of Renal Calculi. The Journal of Urology, 146, 733-736.

https://doi.org/10.1016/S0022-5347(17)37908-9 